\title{
Diversificação Produtiva e Forma de Organização dos Agricultores Familiares: Um Estudo de Caso do PAA no Município de Caxias-MA
}

\author{
Joabe Alves Carneiro $^{1}$ Adriana Estela Sanjuan Montebello ${ }^{2}$
}

\begin{abstract}
RESUMO
O estudo tem como objetivo verificar, por meio de um estudo de caso no município de Caxias-MA, a ocorrência da diversificação da produção familiar antes e depois do PAA bem como aferir se o programa tem contribuído para a organização dos agricultores em associações/cooperativas, e se tem estimulado a revitalização das organizações como forma de facilitar a operacionalização do programa. A metodologia consistiu na aplicação de 44 formulários semiestruturados aos agricultores. Como principais resultados, verificou-se que antes do PAA, os agricultores produziam 11 tipos de diferentes culturas. Com a participação no mercado institucional via o PAA, estes agricultores passaram a cultivar 30 tipos de culturas diferentes. A pesquisa também identificou o desinteresse dos beneficiários que fazem parte do PAA em participar de associações e cooperativas. Conclui-se que o associativismo e o cooperativismo rural são uma realidade para o enfrentamento de crises econômicas para os pequenos produtores rurais, entretanto, o perfil dos beneficiários do PAA no município de Caxias não apresenta relação direta ou forte vínculo com o associativismo e o cooperativismo.
\end{abstract}

Palavras-chave: 1 Cooperativismo; 2 Associativismo; 3 Agricultura Familiar.

\begin{abstract}
The study aims to verify, through a case study in the municipality of Caxias-MA, the occurrence of diversification of family production before and after the PAA, as well as to assess whether the program has contributed to an organization of farmers in associations / cooperatives, and the revitalization of associations has been encouraged as a way to facilitate the operationalization of the program. The methodology consisted of applying 44 semi-structured forms to farmers. As main results it was found that before the PAA, farmers produced 11 types of different crops. With the participation in the institutional market via PAA, they started to cultivate 30 different types of cultures. The survey also identifies the lack of interest of beneficiaries who are part of the PAA in the participation of associations and cooperatives. It is concluded that associativism and rural cooperativism are a reality for facing crises for small rural producers, however, the profile of PAA beneficiaries in the municipality of Caxias does not have a direct relationship or strong link with associativism and cooperativism.
\end{abstract}

Keywords: 1 Cooperatives; Association and Family Farming.

${ }^{1}$ Instuição de afiliação 1:Universidade Federal de São Carlos. Programa de Pós-Graduação em Agroecologia e Desenvolvimento Rural. * E-mail: Joabecarneiro@ifma.edu.br

2 Instuição de afiliação 2: Universidade Federal de São Carlos. Programa de Pós-Graduação em Agroecologia e Desenvolvimento Rural.*E-mail: adrianaesm@ufscar.br 


\section{INTRODUÇÃO}

O Programa de Aquisição de Alimentos (PAA) foi instituído pela Lei nº 10.696 de 2003 com o objetivo de reduzir a fome e a pobreza no Brasil. A referida lei passou por modificações ao logo dos anos de existência com desígnio de melhorar a operacionalização do programa; ampliar o número de atendimentos de produtores rurais beneficiados e pessoas beneficiárias consumidoras; promover a inclusão social e econômica com fomento à produção sustentável, o processamento de alimentos e a geração de renda na Agricultura Familiar (AF).

O PAA é operacionalizado pela Secretaria de Agricultura Familiar e Cooperativismo (SAF) que desenvolveu as modalidades de atuação, as quais foram adaptadas para atender ao público dos produtores rurais. As modalidades atuais são: Compra da Agricultura Familiar para Doação Simultânea, Formação de Estoques pela Agricultura Familiar - CPR Estoque, Compra Direta da Agricultura Familiar CDAF, Incentivo à Produção e Incentivo de Leite - PAA Leite e Compra Institucional, tendo cada uma suas característica e funcionalidades (MDA, 2018).

Os beneficiários fornecedores são agricultores familiares, assentados da reforma agrária, silvicultores, aquicultores, extrativistas, pescadores artesanais, indígenas e integrantes de comunidades remanescentes de quilombos rurais e de demais povos e comunidades tradicionais, que atendam aos requisitos previstos no art. $3^{\circ}$ da Lei $n^{\circ} 11.326$, de 24 de julho de 2006.

Para participar do Programa, os beneficiários fornecedores devem estar inscritos no Cadastro de Pessoas Físicas - CPF da Receita Federal do Brasil do Ministério da Fazenda, e possuírem a Declaração de Aptidão ao PRONAF - DAP, podendo participar do Programa qualquer um dos titulares da DAP. As informações do cadastro dos beneficiários fornecedores estão disponíveis no sistema do PAA - o SISPAA. O SISPAA é alimentado pela base de dados da DAP, gerida pela SAF.

Desta forma, o PAA passou a contribuir para o fortalecimento da agricultura familiar. Conforme Agapto et al. (2012), o PAA tem a missão de fortalecer a agricultura familiar, possibilitando a formação de estoques e/ou a comercialização de seus produtos a preços mais justos e concomitantemente assegurando alimentação às populações em situação de insegurança alimentar e nutricional, preconizando que o consumo dos produtos doados se dê dentro da mesma região produtora. Cyntrão 
(2018) também apresenta o PAA como uma política pública inovadora, com o objetivo de garantir a comercialização dos produtos advindos da agricultura familiar, estimulando a dinâmica local e o desenvolvimento rural, distribuindo estes alimentos às pessoas que se encontram em situação de insegurança alimentar e nutricional. Desde a institucionalização do PAA em 2003, mudanças ocorreram dentro do programa com a finalidade de melhorar o acesso dos agricultores e contribuir com meios de produção com menor agressividade ao meio ambiente.

Para tanto em outubro de 2011, foi elaborada a Lei 12.512, que institui o Programa de Apoio à Conservação Ambiental e o Programa de Fomento às Atividades Produtivas Rurais, com o objetivo de incentivar a conservação dos ecossistemas, bem como promover a melhoria de condições de vida e a elevação da renda da população de extrema pobreza.

Com estas alternativas, a Lei 12.512 de 2011 desburocratizou o programa que resultou na ampliação do número de beneficiários fornecedores para o PAA. Desta forma, o Executivo Federal, Estadual, Municipal e do Distrito passaram a adquirir alimentos produzidos pelos beneficiários do programa, rompendo uma importante barreira institucional (dispensando o procedimento licitatório) desde que os preços sejam justos e de acordo com o mercado (BRASIL, 2019). Em 2015, com a finalidade de maior ampliação da participação dos agricultores familiares nas Compras Institucionais, com a edição do Decreto $n^{\circ} 8.473$, de 22 de junho de 2015, tornou-se obrigatória a aquisição de alimentos de agricultores familiares e suas organizações, empreendedores familiares rurais e demais beneficiários no percentual mínimo de $30 \%$ do total dos recursos recebidos para aquisição de gêneros, conforme o art. $1^{\circ}$ do referido Decreto. Muitos estudos apontam os benefícios e importância do PAA para o desenvolvimento local e nacional.

Grisa e Schneider (2015) destacam que o surgimento do PAA, em 2003, caracterizou-se como elemento fundamental na construção de mercados para a segurança alimentar e a sustentabilidade ambiental, abrindo uma "janela de oportunidades" e gerando aprendizados para a construção de novas ações. Ainda, os mesmos autores destacam a importância da quebra das barreiras institucionais (como a Lei de Licitações $\mathrm{n}^{\circ} 8.666$ de 1993), neste caso, dispensando o processo de licitação, para aquisição de alimentos produzidos pelos beneficiários do PAA. Desta 
forma, desencadeou uma nova trajetória para os mercados institucionais dentro da agricultura familiar.

Assis et al. (2017) levantaram sete trabalhos presentes na literatura, sendo que o objetivo era buscar avaliar a importância do impacto do Programa de Aquisição de Alimentos na diversificação da produção, autoconsumo e segurança alimentar e nutricional dos agricultores familiares participantes como beneficiários fornecedores.

Os trabalhos analisados por Assis et al. (2017) foram os de: a) Mattei (2007) cujo estudo foi realizado no Estado de Santa Catarina nos municípios de São Miguel do Oeste, Guaraciaba e Dionísio Cerqueira; b) Deser (2008) na região Nordeste nos estados da Bahia, Pernambuco e Ceará; c) Becker e Sacco dos Anjos (2010) no estado do Rio Grande do Sul nos municípios de Pelotas, Canguçu e São Lourenço do Sul; d) Santos et al. (2010) no Estado de Minas Gerais e Bahia; e) Hespanhol (2013) cujo estudo foi feito no estado de São Paulo no município de Dracena e, f) Silva e Almeida (2013) em que o trabalho teve como foco estudar o Polo Borborema no estado da Paraíba.

Assis et al. (2017) descreve os mais citados benefícios do PAA que contribuem para o desenvolvimento da economia agrícola com base nos trabalhos supracitados. Desta forma, observa-se que no trabalho de Deser (2008), o programa encorajou os produtores a investirem em capacitação profissional e reestruturação dos sistemas de produção, adequando-os às práticas agroecológicas ou aquelas que utilizavam em menor grau insumos químicos.

Outras melhorias efetivas foram a ampliação da área cultivada, e o aumento da produção e da produtividade, percebido nos estudos de Mattei (2007), Santos et al. (2010), Deser (2008) e Hespanhol (2013) apud Assis (2017). Ainda, Assis et al. (2017) observou que Mattei (2007) destacou o progresso tecnológico na unidade produtiva. Silva e Almeida (2013) apontaram a especialização para o trabalho na agroindustrialização. Já Deser (2008), Becker e Sacco dos Anjos (2010) enfatizaram o resgate e a valorização de práticas agrícolas e dos produtos tradicionais. Silva e Almeida (2013), com o objetivo de avaliarem a experiência do PAA, por intermédio da modalidade Compra com Doação Simultânea para a aquisição de sementes crioulas, no Polo de Borborema, conforme supracitado, visualizaram um conjunto de resultados importantes para o fortalecimento da estratégia de produção e 
comercialização, entre eles, a retomada de estratégias tradicionais de cultivo como os consórcios que diversificam a alimentação e os produtos a serem comercializados.

Para tanto, Assis et al. (2017) concluíram que em todos os estudos levantados foram determinantes o papel do PAA na diversificação produtiva, pois o programa abarca vários grupos de alimentos, tanto in natura quanto processados, o que também influenciou positivamente na manutenção ou mesmo no incremento das práticas de autoconsumo, promovendo a segurança alimentar e nutricional do grupo familiar, visto que consumiam uma variedade de alimentos produzidos pelo próprio grupo familiar, observando os hábitos locais e reproduzindo um cenário relevante para a qualidade de vida no meio rural.

Na reflexão de Bergamasco, Borsatto e Souza-Esquerdo (2013) sobre o PAA, a partir de estudos de casos no estado de São Paulo, o programa permitiu a melhora do poder aquisitivo do produtor rural. Nos municípios estudados pelos autores, foi possível verificar que o PAA tem colaborado para diferentes mudanças positivas, entre elas, o sucesso do fortalecimento de circuitos locais e regionais de distribuição de alimentos, bem como as redes de comercialização. Além disso, os agricultores pesquisados informaram que o PAA impactou positivamente na renda de suas famílias, contribuiu para a manutenção de uma renda fixa por mês e despertou, entre os agricultores, o interesse da diversificação produtiva, com a finalidade de reduzir os riscos inerentes à produção, aumentando significativamente as atividades desenvolvidas pelas famílias rurais, visando garantir a subsistência e a produção de excedentes para a comercialização, e com a finalidade de minimizar a dependência de poucos produtos o que reflete na segurança alimentar do núcleo familiar.

Desta forma, o PAA gera efeitos positivos para os agricultores que desempenham uma função de utilidade pública ao proporcionar a doação de alimentos saudáveis e (quase sempre) diversificados às entidades sociais. Souza e Loreto (2018) mostraram a relevância das compras de produtos da agricultura familiar pelo PAA no estado de Minas Gerais, entre tais, a diversificação da produção, construção de mercados para a comercialização dos produtos e a geração de renda adicional para as unidades familiares.

Segundo Souza e Loreto (2018) ocorreram alterações nos modos de produção agrícolas como as práticas no manejo da produção, dada a influência da assistência técnica prestada pela EMATER aos agricultores participantes do programa. O 
aumento da diversificação e melhoria da qualidade de produção ampliaram as possibilidades de alimentos comercializáveis e, consequentemente, os rendimentos dos agricultores; além de aumentar a proximidade entre os produtores e consumidores, gerando confiança e sentimento de comprometimento entre ambos. Tratando-se de estudos de caso nos municípios brasileiros, podem ser citados, por exemplo, os estudos de Cunha, Freitas e Salgado (2017) e Carneiro e Montebello (2019).

Cunha, Freitas e Salgado (2017) procuraram compreender a dinâmica socioeconômica da agricultura familiar no município de Espera Feliz, em Minas Gerais, por meio da análise dos programas governamentais de aquisição de alimentos, o PAA e o Programa Nacional de Alimentação Escolar - PNAE. Na visão de Cunha, Freitas e Salgado (2017), o PAA beneficia não apenas às entidades socioassisten ciais e agricultores familiares, mas toda uma rede de relações estabelecidas entre a produção e o consumo. Desta forma, o PAA torna-se um aliado da economia local, buscando fomentar o desenvolvimento da agricultura familiar. Além disso, o estudo destaca o incentivo gerado pelo programa à participação de mulheres no mercado e o cultivo de alimentos orgânicos, bem como da sociobiodiversidade.

Além disso, o estudo de Carneiro e Montebello (2019) abordou os aspectos econômicos e sociais do PAA no município de Caxias no Estado do Maranhão, em que os objetivos foram analisar o perfil socioeconômico das famílias beneficiadas com o programa e o funcionamento do processo de compras e canais de comercialização. A pesquisa apontou que $100 \%$ dos agricultores pesquisados afirmam que tiveram melhorias em suas rendas com a venda para o PAA, 82\% opinaram que os preços estão acima dos praticados no mercado local, $7 \%$ iguais aos praticados no mercado e $1 \%$ dos pesquisados afirmaram que em alguns produtos o mercado local paga melhor. Enquanto aos preços que se paga, 95,5\% julgam como sendo justos. A pesquisa dos autores mostra que o PAA trouxe resultados positivos e fomentou o desenvolvimento rural, a inclusão social e produtiva, a valorização do trabalho e reconhecimento da importância dos agricultores familiares. Carneiro e Montebello (2019) também destacam que o programa necessita de melhorias contínuas em seus processos operacionais, a fim de evitar desconfortos relativos à comercialização, transporte, pontualidades de pagamento, documentação, assistência técnica e capacitação, dentre outros. 
As contribuições dos estudos realizados pela literatura mostram a importância do PAA como uma política de desenvolvimento para a agricultura familiar no Brasil. Além disso, diante deste contexto e dos resultados apontados pelos autores pesquisados, notou-se a necessidade de verificar se o programa tem contribuído para a organização dos agricultores em associações/cooperativa, e se tem estimulado a revitalização de organizações como forma de contribuir para o acesso às políticas públicas e também para o fortalecimento da agricultura familiar.

Assim, a presente pesquisa tem como objetivo verificar, por meio de um estudo de caso, a ocorrência da diversificação da produção familiar antes e depois do PAA bem como aferir se o programa tem contribuído para a organização dos agricultores em associações/cooperativa, e se tem estimulado a revitalização das organizações como forma de facilitar a operacionalização do programa. Leva-se em consideração que o estudo anterior de Carneiro e Montebello (2019) não abordou a importância do PAA com relação a diversificação, cooperativismo e associativismo.

O município de Caxias apresenta grande potencial para que seja desenvolvida políticas públicas geradoras de renda e inclusão social. Dados do Censo Demográfico de 2019, levantados pelo Instituto Brasileiro de Geografia e Estatística (IBGE) trazem que, no ano em questão, a população estimada do município de Caxias era de 164.880 habitantes.

A cidade situa-se na mesorregião do leste maranhense e na microrregião do Itapecuru e pertence ao Território de Desenvolvimento dos Cocais. Sua extensão territorial é de uma área de 5.196, $76 \mathrm{Km}^{2}$ e está a 365 quilômetros da capital do Maranhão, São Luís (IBGE,2019).

Segundo a Secretaria de Agricultura do Município de Caxias-MA, em relação ao PAA, em 2018, o número de famílias atendidas pelo Programa passaria de 136 para quase 400 famílias em mais de 30 povoados.

$\mathrm{O}$ artigo se estrutura em seis seções, além desta introdução. $\mathrm{Na}$ primeira, conforme já exposto, foi realizada a introdução ao assunto buscando contextualizar o PAA e apresentar os objetivos do presente estudo. A segunda seção apresenta o referencial teórico relativo à diversificação produtiva e forma de organização dos agricultores. Na terceira seção são apresentados os aspectos metodológicos. Na quarta seção são apresentados os resultados e a discussão da pesquisa e a quinta e sexta 
seção trazem, respectivamente, as considerações finais e as referências bibliográficas utilizadas no artigo.

\section{REFERENCIAL TEÓRICO}

\section{1 - Diversificação produtiva}

Esta parte do referencial teórico busca refletir sobre a diversificação da produção familiar e a importância da organização solidária, cooperativismo e associativismo como alternativa de facilitar o trabalho conjunto fortalecendo a agricultura familiar.

Para que a diversificação da produção tenha retornos e sustentabilidade econômica, será imprescindível atacar veemente as barreiras que impedem os produtores de abraçarem os sistemas diversificados. Entre os principais obstáculos à diversificação, podem ser destacados: a) a falta de conhecimento tecnológico para implantar e gerir sistemas diversificados que sejam eficientes e sustentáveis; b) a baixa disponibilidade de mão de obra para viabilizar sistemas que sejam mais intensivos em trabalho, face à maior dificuldade de mecanizar cultivos; c) as dificuldades de comercialização e de infraestrutura de beneficiamento, armazenamento e transporte inerentes à menor escala de produção; e d) a falta de capital para bancar as mudanças invocativas (SAMBUICHI et al., 2014).

A produção em sistemas diversificados passou, então, a ser vista por muitos como atraso tecnológico, relacionada à cultura de subsistência e à pobreza rural nos países em desenvolvimento, onde a modernização tecnológica não conseguiu chegar. O fato é que em muitos casos, os agricultores mais pobres diversificam a sua produção para ter o que comer (SAMBUICHI et al., 2014). Desta forma, a diversificação da produção agrícola pode ser uma ferramenta eficaz para ajudar os agricultores a lidar com vários tipos de riscos, incluindo o risco de preço e produtividade, o risco nos mercados de insumos (por exemplo no mercado de trabalho) e outros riscos de mercado como o risco por não encontrar um comprador para o seu produto (BOWMAN e ZILBERMAN, 2013, tradução nossa).

Schneider (2010) estudou a diversidade na agricultura brasileira em diferentes níveis de análise. Na Figura 1, os Quadros 1,2,3 indicam os níveis de análise da diversificação; e no Quadro 4 é indicada a influência que cada nível pode exercer em relação a diversificação da produção agrícola dos agricultores. 
Figura 1 - Representação esquemática dos níveis de diversificação.

Quadro 1

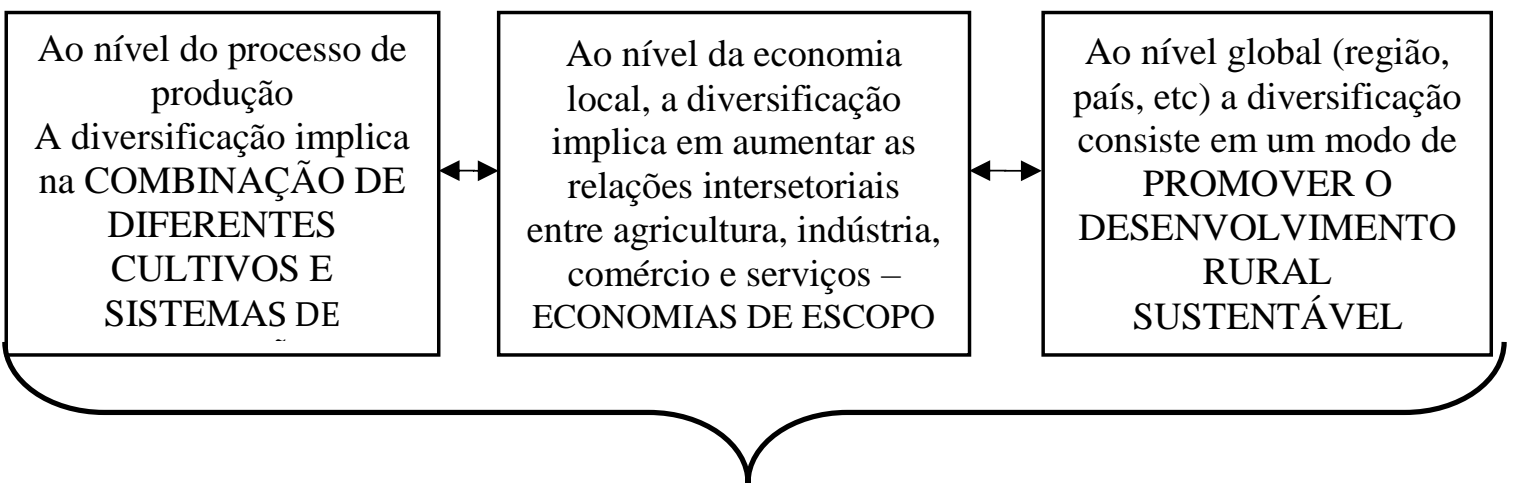

Quadro 4

Q1 Aumento de atividade e produtos ofertados pelos agricultores, o que amplia as alternativas para sua inserção nos mercados e reduz a sazonalidade e estagnação da renda agrícola. Reduz a dependência das flutuações setoriais de preços. Novas formas de manejo e uso de plantas, dos animais e do espaço, tornando as propriedades e a própria paisagem diversificada. Satisfação dos agricultores diversificados tende a ser maior porque possuem maior interação com os consumidores/clientes ou mesmo com a comunidade local.

Q2 Criar ambientes favoráveis à integração setorial entre agricultura, comércio, indústria e serviços. Diversidade regional pode gerar maior estabilidade e reduzir as vulnerabilidades decorrentes das flutuações do mercado de trabalho e das fontes de renda.

Q3 Diversificações podem ser a base sobre a qual se erguerá uma forma de desenvolvimento mais plural e democrática, que não apenas irá tolerar a alteridade, mas a estimulará e cultivará.

Fonte: Schneider (2010), adaptado

\subsection{Forma de organização dos agricultores}

\subsection{1 - Cooperativas}

Segundo Costa et al (2015), o cooperativismo dispõe de liberdade e independência, sendo que este tipo de relação teve início em Rochdale (Inglaterra) em 1844. Tratava-se da constituição (por iniciativa de 28 operários) da primeira organização que foi denominada cooperativa, a dos Pioneiros Equitativos de Rochdale. Entretanto, a cooperativa de Rochdale surgiu não apenas com o objetivo de fornecer alimentos de melhor qualidade a preços mais justos, mas também tinha preocupação com a educação dos sócios, bem como de seus familiares segundo Cançado (2004 apud, Costa et al. 2015).

Costa et al (2015) afirmam que, no Brasil, no início do cooperativismo agropecuário, o incentivo era para produção exportadora, e assim este modelo beneficiou 
os produtores que detinham grandes extensões de terra e privilegiavam a monocultura, desta forma, o interesse dos agricultores familiares não eram considerados. Após a crise econômica mundial no final dos anos 1920, o governo brasileiro entende que o cooperativismo tem a possibilidade de amenizar alguns problemas gerados pela crise e incentiva a constituição de cooperativas agropecuárias, sobretudo as cooperativas que conseguissem escoar a produção da pequena propriedade (COSTA et al, 2015).

O cooperativismo brasileiro é amparado pela Lei $\mathrm{n}^{\circ} .5 .764$ de 16 de dezembro de 1971, exige um número mínimo de vinte sócios para a sua constituição e é representado, formalmente, pela Organização das Cooperativas Brasileiras-OCB, que é uma entidade que congrega todas as cooperativas brasileiras, de todos os ramos e que representa formal e politicamente o sistema nacional.

A OCB enxerga o cooperativíssimo como mais que um modelo de negócios, uma filosofia de vida que busca transformar o mundo em um lugar mais justo, feliz, equilibrado e com melhores oportunidades a todos. De acordo com a OCB (2019), no Brasil, o cooperativismo pode ser aplicado aos mais variados tipos de negócios, por exemplo, as cooperativas agrícolas e agropecuárias que têm por vocação principal ajudar seus associados (produtores rurais) a comercializar, da melhor maneira possível, suas produções, conseguindo bons compradores e preços para os produtos agropecuários. Com o ganho de escala na produção, os cooperados conseguem fazer grandes negócios, inclusive exportações.

Para Cremonese e Schallenberger (2005), as cooperativas, são entendidas como associações de indivíduos que buscam de forma solidária a obtenção de resultados econômicos que permitam a melhoria da economia individual e coletiva. Para Bialoskorski Neto (2006), o cooperativismo está além da busca de resultados econômicos, configurando-se como uma missão de promover a integração do produtor à cadeia produtiva.

De acordo com Sousa (2000), o cooperativismo permite em sua essência outros ganhos diferentes além dos econômicos em si, tais como a autoestima, identificação com o trabalho e com o grupo produtivo, companheirismo, além de uma noção crescente de autonomia e de direitos de cidadãos.

Dessa forma, o cooperativismo pode proporcionar melhoria das condições econômicas dos produtores, principalmente, para os pequenos agricultores que ficam restringidos a comercialização do excedente da produção. 


\subsection{2 -Associativismo}

$\mathrm{O}$ associativismo não é recente no Brasil. O movimento vem atuando desde o século XIX. Neste período, as sociedades englobavam entidades beneficentes, religiosas, literárias, desportivas, cooperativas, entre outras modalidades de associação (JESUS, 2007).

Leopoldino (2015) levantou vários estudos referentes ao associativismo, e apontou benefícios proporcionados pela associação dos indivíduos, e suas conquistas, abrangendo aspectos econômicos e não econômicos. Segundo o autor, a literatura registra casos envolvendo sindicatos de trabalhadores, pequenos produtores, o movimento negro, o dos indígenas e as lutas das mulheres por melhores condições de vida (LOPES; BAUER, 2015; SOUZA et al., 2015; MAGALHÃES; SCHEMES, 2014; PERES, 2011; JESUS, 2007; LAVALLE; CASTELLO, 2004). Por meio destes estudos, é possível verificar que a exploração do potencial do associativismo consiste em possibilidade real de melhoria de vida para os envolvidos (LEOPOLDINO, 2015).

Para tanto, o associativismo tem por essência proporcionar benefícios técnicos, profissionais, econômicos e sociais a determinados grupos de indivíduos que expressam interesses homogêneos (SANGALLI et al., 2015). Oferece ainda a possibilidade de um ambiente de comunicação harmônica entre os indivíduos que dela participam. Criam um ambiente flexível, caracterizado pelo fato de que distintos atores interagem, o que resulta num produto harmônico no estabelecimento de uma comunidade de interesses (SANGALLI et al., 2015).

No estudo de Oliveira (2010), referente ao associativismo na região do Pontal do Paranapanema-SP, observou-se que tanto as cooperativas, como as associações, têm um papel elementar no processo contributivo com a organização da produção da agricultura familiar. É destacado que nos assentamentos rurais, estas formas associativas têm se estabelecido de forma expressiva, o que reflete uma melhora do nível de produção dos agricultores familiares. Essa contribuição pode ocorrer de forma econômica, política, social e cultural, sendo visto também em outras regiões (LEOPOLDINO, 2015; SANGALLI et al., 2015; TYGEL 2014; CREMONESE \& SCHALLENBERGER, 2005; SANGALLI et al., 2015).

É importante frisar que as existências destes modelos de economia como o cooperativismo e associativismo podem exercer influências positivas nos resultados da 
comercialização de produtos da agricultura familiar. Para que isto seja comprovado, basta reportar ao estudo de Sambuichi (2014) que levantou 29 estudos sobre o PAA dos quais $52 \%$ dos estudos mostraram que a relação dos agricultores familiares com as organizações, seja elas, cooperativas ou associações contribuíram para fomentar a comercialização dos produtos produzidos pelos agricultores.

Embora, o associativismo e cooperativismo guardem semelhanças, Leonello e Cosac (2008) afirmam que o associativismo, assim como outras formas de movimentos sociais, possui suas especificidades e características, pois existem diferenças regionais, no grau de seu desenvolvimento, de sua compreensão, organização e planejamento, o que denota falta de educação formal para que se estabeleça. Entretanto, pode-se afirmar que a essência do associativismo rural consiste em uma atividade organizacional coletiva que tem como finalidade conquistar benefícios comuns para os sujeitos que a compõem, respeitando a cultura local sem nenhum fim lucrativo. Desta forma, as práticas associativas é fruto da constante luta social no espaço rural por melhores condições de vida, por um reconhecimento que proporcione certa integração no cenário social, econômico e cultural.

Para Cardoso (2014), a associação apresenta desvantagem em relação à cooperativa, ela engessa o capital e o patrimônio, ou seja, o patrimônio acumulado pertence à associação e não aos seus associados.

Desta forma o associativismo e o cooperativismo são organizações sociais diferentes. Entretanto, vale frisar que a importância do associativismo está na adoção das formas de agir em conjunto, estimulando a confiança, a ajuda mútua, o fortalecimento e o empoderamento das pessoas. O cooperativismo é utilizado quando um grupo de pessoas se une e forma uma cooperativa, que é uma empresa de sociedade coletiva. As cooperativas apresentam finalidades mais direcionadas para o viés econômico, ao buscar viabilizar a inserção dos seus membros junto ao mercado sendo que as associações, por sua vez, tendem a ir além e abraçam outras questões de ordem cultural, educacional, socioassistencial segundo Balem (2015, p.28).

\section{METODOLOGIA E FONTE DE DADOS}

A metodologia do presente estudo consiste na aplicação de formulários semiestruturados aos agricultores da amostra pesquisada. Os dados primários foram obtidos a partir da aplicação de 44 formulários aos agricultores participantes do PAA no município de Caxias. 
A amostra dos 44 formulários refere-se aos Beneficiários Fornecedores do Programa de Aquisição de Alimentos (PAA) do município de Caxias no Estado do Maranhão. Os procedimentos que antecederam a pesquisa foram realizados respeitando o parecer consubstanciado do Conselho de Ética na Pesquisa (CEP). No momento da pesquisa, os participantes assinaram o Termo de Consentimento Livre e Esclarecido.

Agrononik e Hirakata (2011) esclarecem que o tamanho da amostra pode depender de muitos fatores tais como: a variável de interesse no estudo, o tipo de variável (quantitativa ou qualitativa), a existência ou não de comparação entre grupos (objetivo do estudo), a quantidade de grupos envolvidos, o poder do teste, o nível de significância e o tamanho do efeito. Caso exista mais de um desfecho de interesse, o tamanho da amostra deve ser calculado para cada desfecho. Para chegar ao tamanho da população finita de 82 agricultores, utilizou-se as informações da base de dados da plataforma PAA Data, a qual está vinculada a Secretária de Informação e Gestão da Informação (SAGI) do MDS no ano de 2018.

A Secretaria de Gestão e Avaliação da Informação (SAGI) do MDS é responsável pelo monitoramento de dados, indicadores e análise de estudos dos programas sociais do governo. Para se alcançar a quantidade de formulários a ser aplicado, utilizou-se a seguinte expressão conforme Agrononik e Hirakata (2011):

$$
n=\frac{p(1-p) Z^{2} N}{\varepsilon^{2}(N-1)+Z^{2} p(1-p)}
$$

Onde:

$\mathrm{n}=$ tamanho da amostra

p: proporção esperada (quando não há informação sobre a proporção de interesse, uma das formas de solucionar este problema e supor que ela seja de 0,50 ).

Z: Valor da distribuição normal para determinado nível de confiança (90\% ou seja 1,645);

$\mathrm{N}$ : tamanho da população (82 agricultores);

$\varepsilon$ : tamanho do intervalo de confiança (margem de erro $10 \%$ ou seja 0,01 ). 
Considerou-se uma margem de erro de $10 \%$ e um nível de $90 \%$ de confiança e proporção esperada de $50 \%$, sendo que o número final encontrado, ajustado para populações finitas, foram de 38 agricultores conforme a metodologia de Agrononik e Hirakata (2011). Aplicou-se 44 formulários aos agricultores, sendo que 38 foi o número mínimo encontrado de agricultores a ser aplicado o formulário. Neste sentido, os quatro formulários a mais, diante de uma população finita aumentaram o grau de precisão sobre os dados pesquisados. O nível de significância utilizado foi de $10 \%$, que para Levy e Lemeshow (1980 apud Marotti et al. 2008) é um dos níveis de significância com boa aceitabilidade em pesquisas cientificas.

\section{RESULTADOS E DISCUSSÃO}

Na Figura 2 é mostrado o panorama da diversificação produtiva trazida pelo PAA no município de Caxias. No levantamento da pesquisa, foram identificados 26 agricultores que correspondem a 59,09\%, que optaram pela diversificação da produção após começarem a vender para o PAA.

Identificou-se que antes do PAA, os agricultores produziam 11 tipos de diferentes culturas produtivas. Com a chegada do programa, estes agricultores passaram a cultivar 30 tipos de culturas diferentes. Entre as culturas com maior preferência dos agricultores antes do PAA (Figura 2), foram: o milho 47,73\%, feijão 43,18\%, macaxeira $29,55 \%$, arroz $29,55 \%$ e mandioca $27,27 \%$.

Figura 2 - Frequência das culturas produtivas realizada antes da participação do agricultor no PAA no município de Caxias-MA.

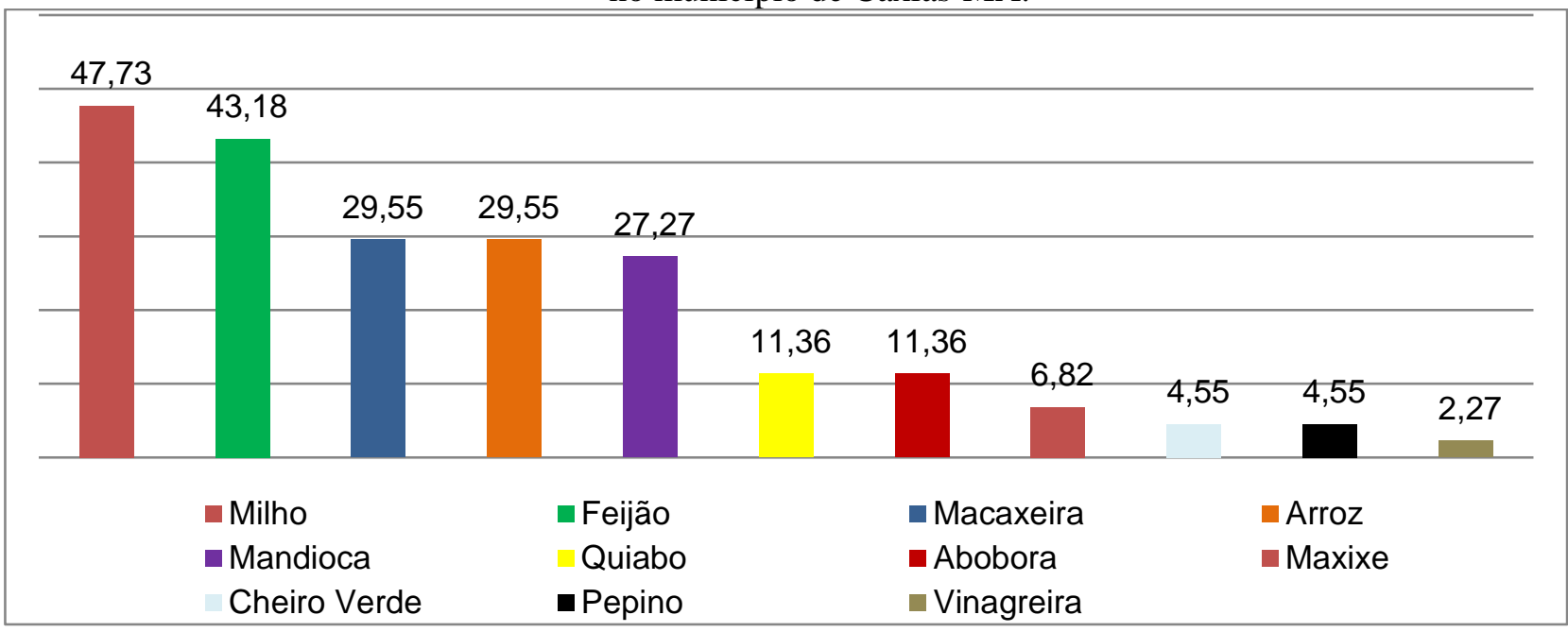

Fonte: Pesquisa de campo, (2019). 
Após a entrada no programa com o incentivo da Secretaria de Agricultura do Município à diversificação, decorrente principalmente da demanda variada por alimentos entregues às entidades beneficiadas, foram observadas, conforme a Figura 3, a seguinte frequência das cinco maiores culturas produtivas: maxixe $(34,09 \%)$, abóbora $(31,82 \%)$, milho $(31,82 \%)$, feijão $(27,27 \%)$ e vinagreira $(29,55 \%)$.

Figura 3 - Frequência das culturas produtivas depois da participação do agricultor no PAA no município de Caxias-MA.

\begin{tabular}{|c|c|c|}
\hline Maxixe & & 4,09 \\
\hline Abobora & 31,82 & पMaracujá \\
\hline Milho & 31,82 & 口Goiba \\
\hline Vinagreira & 29,55 & aFafa \\
\hline Feijão & 27,27 & nAta (fruta do \\
\hline Cheiro Verde & 27,27 & conde) \\
\hline Mandioca & 27,27 & aCoco \\
\hline Alface & 20,45 & ¿Bananna \\
\hline Pepino & 20,45 & 口Melão \\
\hline Quiabo & 20,45 & 口imão \\
\hline Pimentinha & $\longrightarrow 15,91$ & \\
\hline Melância & 15,91 & aBeringela \\
\hline Cebola (folha) & 13,64 & aCouve \\
\hline Pimentão & $\square$ 13,64 & 口Tomate \\
\hline Couve & 11,36 & ¿Mamão \\
\hline Arroz & 9,09 & 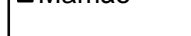 \\
\hline Batata & $\square, 09$ & 口Acerola \\
\hline Acerola & $\Longrightarrow 9,09$ & aBatata \\
\hline Mamão & 9,09 & Arroz \\
\hline Tomate & 9,09 & - \\
\hline Couve & $\square$ 9,09 & DCouve \\
\hline Beringela & $\longrightarrow$ 6,82 & 口Pimentão \\
\hline Limão & 6,82 & aCebola \\
\hline Melão & $\begin{array}{l}\square, 82 \\
\end{array}$ & $\begin{array}{l}\text { (folha) } \\
\text { a Melância }\end{array}$ \\
\hline Bananna & 4,55 & \\
\hline Coco & $\Longrightarrow$ 4,55 & aPimentinha \\
\hline Ata (fruta do conde) & $\longrightarrow 2,27$ & ¿Quiabo \\
\hline Fafa & $\longrightarrow 2,27$ & 口Pepino \\
\hline Goiba & $\longrightarrow 2,27$ & \\
\hline Maracujá & $\Longrightarrow$ 2,27 & \\
\hline
\end{tabular}

Fonte: Pesquisa de campo (2019).

Outro aspecto destacado, do estímulo dado pelo programa à diversificação produtiva, foi que a agricultura familiar (AF) apresenta sistemas mais próximos dos ecossistemas em que está inserida. Entretanto, a maior diversidade de produção agrícola, no âmbito da AF, se deve à busca de diferentes rendas, distribuídas ao longo do ano. Além disso, busca-se o autoconsumo alimentar e a redução de riscos comerciais. A diversidade 
de cultivos é possível em função do agricultor familiar ser ao mesmo tempo empreendedor e trabalhador, de forma que o trabalho e a gestão estão juntos na unidade familiar.

Outro incentivo econômico para os agricultores adotarem os sistemas agrícolas diversificados é o potencial para comercialização de produtos cultivados respeitando a agrobiodiversidade. Esta especialidade de serviços apela para um crescente contingente de consumidores preocupados com os impactos de suas escolhas alimentares em sua saúde e na saúde do meio ambiente (Bowman e Zilberman, 2013, tradução nossa).

$\mathrm{Na}$ Figura 4, o estudo apontou, a partir da inserção dos agricultores no PAA, a redução da concentração de atividade agrícola, a qual abre espaço para o crescimento da diversificação da produção. Percebeu-se que as culturas tradicionais da região tais como milho que representava $47,73 \%$ da produção reduziu sua participação para $31,72 \%$ e o feijão de $43,18 \%$ reduziu sua participação para $27,27 \%$ e a mandioca que antes era de $27,27 \%$ não pontuou na pesquisa após a inserção do PAA. Ao mesmo tempo, outras culturas aumentaram suas participações após o PAA: quiabo, abóbora, maxixe, cheiro verde, pepino e vinagreira.

Figura 4 - Comparação da participação das culturas produtivas antes e depois do PAA em (\%) segundo a pesquisa.

\begin{tabular}{|c|c|c|c|c|c|c|c|c|c|c|c|}
\hline & Milho & Feijão & $\begin{array}{c}\text { Macaxeir } \\
a\end{array}$ & Arroz & $\begin{array}{c}\text { Mandioc } \\
\mathrm{a}\end{array}$ & Quiabo & Abobora & Maxixe & $\begin{array}{c}\text { Cheiro } \\
\mathrm{Vd}\end{array}$ & Pepino & $\begin{array}{c}\text { Vinagreir } \\
a\end{array}$ \\
\hline Antes PAA & 47,73 & 43,18 & 29,55 & 29,55 & 27,27 & 11,36 & 11,36 & 6,82 & 4,55 & 4,55 & 2,27 \\
\hline Depois do PAA & 31,32 & 27,27 & 27,27 & 9,09 & 0 & 20,45 & 31,34 & 34,09 & 27,27 & 20,45 & 29,55 \\
\hline
\end{tabular}

Fonte: Pesquisa de campo, (2019).

Assim, nas Figuras 3 e 4 foi possível verificar as frequências das culturas produtivas antes e depois do PAA. Isto mostra que o envolvimento dos agricultores fez com que aumentasse a diversificação da produção, com o incremento de 19 tipos de cultivo distribuídos entre todos os pesquisados. É notável que a execução do programa no município fez com que muitos ampliassem a diversidade de cultivos, incluindo especialmente hortaliças e legumes.

Consequentemente, a diversificação da produção tem contribuído expressivamente para a segurança alimentar, não só para os consumidores como também entre os 
agricultores. Todos os agricultores familiares beneficiários pesquisados afirmaram que consomem os alimentos que produzem, mas em proporções diversas, visto que a produção de alguns é mais diversificada que a de outros.

Os agricultores afirmaram ter aumentado o consumo dos alimentos que produzem, enquanto reduziram o consumo de alimentos industrializados após se vincularem ao PAA. Na pesquisa, também se observou o aumento da diversificação dos produtos, utilização do sistema de produção com o uso de insumos externos tais como os agrotóxicos (inseticidas, acaricidas fungicidas, herbicidas e outros), e, também, contribuiu para a instalação de sistemas de irrigação.

\section{1- Formas de Organização dos Agricultores}

A participação efetiva em associações e cooperativas promove a viabilidade econômica dos empreendimentos rurais, isso porque, desponta relações de confiança e reciprocidade. A troca de informações, capacitação e comprometimento dos membros do grupo gera além de maior coesão grupal, melhores resultados e estabilidade econômica, como exemplo pode-se citar a garantia de comercialização dos produtos produzidos pelos beneficiários do PAA.

Diante dessa importância, verificou-se que em Caxias, no estado do Maranhão, existe pouca participação ativa do grupo de agricultores que participaram do estudo. Conforme mostram os relatos a seguir:

"As pessoas que fazem parte do PAA aqui na comunidade não têm interesse de
participar da associação e nem da cooperativa. E os que são membros não tem
compromisso, não sei ao certo, mas acredito que menos de $50 \%$ são realmente
comprometidos com a Associação, os outros permanecem só esperando algum
benefício pra eles, porque eles não têm o espírito de viver em comunidade"
(Produtor Rural Beneficiado do PAA no município de Caxias, 2018).

Percebeu-se com a pesquisa que em todas as comunidades visitadas em CaxiasMA, tanto as associações como as cooperativas apresentaram diversos impedimentos de funcionamento, sendo um deles o desestímulo dos sócios em participar das pautas providas pelos representantes das referidas organizações, que por sua vez, acabaram comprometendo a eficiência de suas funções.

“O povo da comunidade não acredita mais na união, faltam muito nas reuniões, mas mesmo assim ainda vale a pena acreditar na cooperativa, porque ali que se descobre coisas novas, muita das vezes o vizinho está fazendo uma coisa diferente e está dando certo, meu amigo de uma outra comunidade deixou de plantar arroz, feijão e mandioca e passou a cultivar só verduras e deu certo, está vendendo tudo para o governo. O meu sonho é ver todos os membros participando das reuniões para proporem ações e melhorar mais a associação e 
fazer crescê-las" (Produtor Rural Beneficiado do PAA, município de Caxias, 2018).

De modo geral, os entrevistados manifestaram esperança de que as comunidades se desenvolvam por meio de ações das cooperativas e associações, principalmente, no que diz respeito ao escoamento da produção, sendo um dos principais gargalos enfrentados pelos agricultores.

Para alguns entrevistados, as associações e cooperativas deveriam desenvolver ações concretas que possibilitassem manter os jovens no meio rural com rendas e educação formal em Ciências Agrárias e outras áreas de interesse da juventude. Então, na percepção dos produtores rurais entrevistados, as cooperativas e associações deveriam buscar soluções para os problemas sociais existentes nas comunidades, conforme mostra os relatos a seguir:

"Aqui na comunidade não temos acesso às escolas que ensinem nossos jovens as técnicas de plantio, e nem mexer em computadores, eles têm mais facilidade de aprender do que nós. Acho que a associação e a cooperativa deveriam juntar com as autoridades do município e governantes em geral, para procurar meios pra nos ajudar neste sentido, talvez trazendo cursos de hortas, de como adubar a terra, jogar veneno, mexer no computador e outros ensinos que os jovens se interessarem" (Produtor Rural Beneficiado do PAA, município de Caxias, 2018).

Como a questão central desta seção foi analisar as dimensões de participação dos beneficiários do PAA em Associação dos Produtores Rurais e Cooperativas Rurais no município de Caxias-MA, verificou-se a baixa participação destes beneficiários nas referidas organizações. Desta forma, a Tabela 2 mostra os dados quantitativos coletados durante a pesquisa.

Tabela 2- Demonstrativo dos entrevistados da pesquisa

\begin{tabular}{lllll}
\hline Itens & \multicolumn{2}{c}{ Discriminação } & Quantidade & Percentual (\%) \\
\hline $1 . \quad$ Quantidade & total de beneficiários & 44 & $100 \%$ \\
fornecedores do PAA que participaram da aplicação & & \\
do formulário & & \\
2. Quantidade de entrevistados membro de uma & 25 & $56,81 \%$ \\
$\begin{array}{l}\text { Associação } \\
\text { 3. Quantidade }\end{array} \quad$ de & entrevistados & membros de & 7 & $15,9 \%$ \\
uma cooperativa & & & \\
\hline
\end{tabular}




\begin{tabular}{|c|c|}
\hline $\begin{array}{l}\text { 4. Quantidade de entrevistado que já participou } 10 \\
\text { de capacitação referente ao cooperativismo e } \\
\text { associativismo }\end{array}$ & $22,72 \%$ \\
\hline $\begin{array}{l}\text { 5. Quantidade de entrevistado que detém } 15 \\
\text { conhecimento da estrutura/funcionamento de uma } \\
\text { Associação/Cooperativa }\end{array}$ & $34,09 \%$ \\
\hline
\end{tabular}

Fonte: Pesquisa de campo, (2019)

Do universo da pesquisa de 44 participantes, verificou-se que somente $56,81 \%$ e 15,9\% participam, respectivamente, de alguma associação ou cooperativa, isso denota ausência de conexão em trabalharem em grupo enquanto beneficiários do PAA no município de Caxias. A mesma ausência também é perceptível quando se trata de capacitação referente ao cooperativismo e associativismo, sendo observado que $22,72 \%$ dos entrevistados não tiveram treinamentos. De acordo com relato de dois beneficiários do PAA:

"Acho que se a gente recebesse curso de associativismo e cooperativismo desperta mais interesse da comunidade, porque poderíamos obter conhecimento para ir atrás dos nossos direitos" (Produtor Rural Beneficiado do PAA, município de Caxias, 2018).

"Estes cursos deveriam vir por parte da Secretaria de Agricultura e do Sindicato dos Trabalhadores Rurais, nós aqui na roça nem sabemos como conseguir pessoas pra vir ministrar estes cursos pra gente" (Produtor Rural Beneficiado do PAA, município de Caxias, 2018).

A Tabela 2 deixa evidente a necessidade de reforçar ações para o fortalecimento das organizações com capacitação dos associados e cooperados, promovendo formação política participativa das comunidades.

É importante destacar que pelo Plano Nacional de Desenvolvimento Rural Sustentável e Solidário- PNDRSS, lançado no ano de 2013, é possível verificar a importância de projetos associativos e cooperativos para o desenvolvimento rural no Brasil.

O PNDRSS é fruto do amplo e intenso debate realizado entre as três esferas do governo e a sociedade, ocorrida, em 2013, na $2^{\text {a }}$ Conferência Nacional de Desenvolvimento Rural Sustentável e Solidário. Os objetivos, metas e iniciativas foram 
estabelecidas em: curto, médio e longo prazo para o desenvolvimento do rural brasileiro. Desta forma o PNDRSS estabelece os seguintes itens:

- Inserir em projetos associativos e cooperativos a garantia de $20 \%$ (como percentual mínimo) de jovens contemplados nas atividades de produção das agroindústrias e comercialização, bem como nas atividades agrícolas e não agrícolas, priorizando a inovação tecnológica baseada na matriz agroecológica.

- Estimular a organização das cooperativas e demais organizações econômicas em centrais, redes e outros arranjos voltados para a comercialização de produtos agroecológicos no âmbito municipal, estadual, nacional e internacional.

- Promover arranjos produtivos que fortaleçam a organização econômica da agricultura familiar, em sua diversidade produtiva, social e ambiental.

- Ampliar a capacidade de gestão produtiva e de comercialização, fortalecendo o associativismo e o cooperativismo solidários.

- Aproximar agricultores familiares do mercado consumidor, favorecendo circuitos curtos de produção e consumo, sem extensas redes de atravessadores; estruturar entrepostos de comercialização com gestão consorciada pelas cooperativas e associações de agricultores/as familiares.

Por meio dos resultados sobre a forma de organização dos agricultores, foi possível perceber a dificuldade de organização em cooperativas, associações ou grupos informais, embora, possuíssem afinidades e objetivos comuns (vender sua produção para o PAA).

No estudo de Costa, Amorim Júnior e Silva (2015) cujo objetivo foi analisar o perfil das cooperativas da agricultura familiar em Minas Gerais, diagnosticadas pelo projeto Nutre Minas, e os condicionantes de acesso às políticas de compras governamentais, principalmente, no que se refere aos grandes centros do estado, também foram apontados gargalos e necessidade de ações concretas em relação às cooperativas de agricultura familiar. Os autores destacam que é necessária uma política estruturante de apoio às cooperativas da agricultura familiar para o abastecimento do mercado governamental, sendo que a existência do programa não é garantia para as cooperativas conseguirem comercializar seus produtos. $\mathrm{O}$ fato de os programas governamentais como o PAA e PNAE (Programa Nacional de Alimentação Escolar) não remunerarem o empreendimento, mas apenas preverem a remuneração do produto, é algo interessante de ser revisto, pois os custos de operacionalização destes programas são arcados pelos 
empreendimentos, ou seja, pelos agricultores familiares. Além disso, Costa, Amorim Júnior e Silva (2015) afirmam ser relevante a formação e capacitação dos cooperados em atividades relacionadas à gestão, ao cooperativismo e às atividades de agroindustrialização. Para tanto, políticas de assistência técnica e extensão rural de acompanhamento sistemático e contínuo são importantes para tornarem os agricultores aptos a gerirem suas cooperativas.

Destaca-se que com o presente estudo, o desencadeamento do espírito associativista e cooperativista no município de Caxias-MA pode partir dos agricultores, como também dos gestores públicos, implementando e operacionalizando ações estruturais para o desenvolvimento local através de organizações como as associações e cooperativas. Esta iniciativa de estimular organizações dos agricultores está em consonância com o Plano Nacional de Desenvolvimento Rural Sustentável e Solidário (PNDRSS) lançado no ano de 2013.

\section{CONSIDERAÇÕES FINAIS}

O Programa de Aquisição de Alimento (PAA) constitui-se em uma importante ferramenta de fortalecimento da agricultura familiar. O programa utiliza processos de comercialização que favorecem a compra direta de produtos de agricultores familiares ou de suas organizações, promovendo a agregação de valor à produção, além de promover a inclusão social no campo por meio do fortalecimento da agricultura familiar e garantir o acesso à alimentos em quantidade, qualidade e regularidade necessárias às populações em situação de insegurança alimentar e nutricional.

A pesquisa mostrou que o programa estimulou a implantação e a ampliação dos cultivos e que $100 \%$ dos participantes do estudo passaram a produzir para atender a demanda do PAA. A pesquisa mostrou que 30 tipos de culturas diferentes são produzidos entre os pesquisados. Esta diversificação produtiva foi estimulada pelo PAA que antes da política havia somente 11 tipos de cultivo. Estes efeitos positivos podem potencializar e incentivar a agricultura familiar a aumentar sua produção.

Para o caso em análise, uma das preocupações refere-se à continuidade da diversificação, visto que os recursos destinados ao PAA sofrem oscilações anualmente. Também se questiona a forma de atuação do programa. Com a minimização dos recursos, as famílias enfrentam situações de insegurança financeira, sendo necessárias estratégias e ações voltadas para o fortalecimento da comercialização da agricultura familiar. 
O associativismo e o cooperativismo rural são uma realidade para o enfrentamento de crises econômicas para os pequenos produtores rurais. Entretanto, o perfil dos beneficiários do PAA no município de Caxias não apresenta relação direta ou forte vínculo com o associativismo e o cooperativismo. Foi levantado que 56,81\% e 15,9\% participam respectivamente de alguma associação ou cooperativa. De maneira geral, os 56,81\% dos associados não apresentam qualquer indício de mobilização social capaz de gerar sinergia no grupo, para buscar alternativas de mudança, pois observa-se falta de capacidade e autonomia para vislumbrar um processo em escala de desenvolvimento social e econômico.

Para construção deste trabalho, a pesquisa delimitou-se em um pequeno grupo de agricultores beneficiários do PAA no município de Caxias no estado do Maranhão, o que pode dar abertura para novas pesquisas. Desta forma, sugere-se a continuidade de estudos sobre o diagnóstico geral da participação dos agricultores familiares em relação às formas de organização em cooperativas, associações e organização solidária em vários outros municípios em que agricultura familiar se faz presente.

\section{REFERÊNCIAS}

Agranonik, M., e Hirakata, V. N. (2011). Cálculo de tamanho de amostra: proporções. Revista do Hospital de Clínicas de Porto Alegre, 31(3), 382-388. Recuperado de http://seer.ufrgs.br/index.php/hcpa/article/view/23574/15837.

AGAPTO, J. P.; BORSATTO, R. S; BERGAMASCO, S. M. P. P. Avaliação do Programa de Aquisição de Alimentos (PAA) em Campina do Monte Alegre, Estado de São Paulo, a partir da percepção dos agricultores. Informações Econômicas, São Paulo, v. 42, n. 2, p.1421, 10 dez. 2012.

ASSIS, S.C.R; PRIORE, SE; FRANCESCHINI, S. C. C. Impacto do programa de aquisição de alimentos na segurança alimentar e nutricional dos agricultores. Ciência e Saúde Coletiva. 2017, v. 22, n.2, p. 617-626. Disponível em: < https://www.scielo.br/pdf/csc/v22n2/1413-8123-csc-22-02-0617.pdf>. Acesso em: 22 set. 2019. http://dx.doi.org/10.1590/1413-81 232017222.02292015.

BALEM, T. A. Associativismo e cooperativismo. Santa Maria, 2016, Colégio Politécnico, UFSM. Disponível em:

<http://estudio01.proj.ufsm.br/cadernos_fruticultura/sexta_etapa/arte_associativismo_co operativismo.pdf $>$.

BERGAMASCO, S. M. P. P; BORSATTO, R. S; SOUZA-ESQUERDO, V. F. Políticas públicas para a agricultura familiar no Brasil: reflexões a partir de estudos de casos no 
estado de São Paulo. Revista Interdisciplinaria de Estudios Agrarios, São Paulo, v. 38, n. 1, p.26-49, 21 jun. 2013.

BIALOSKORSKI NETO, S. Aspectos econômicos das cooperativas. Belo Horizonte: Mandamentos, 2006.

BOWMAN, M. S.; ZILBERMAN, D. Economic Factors Affecting Diversified Farming Systems. Ecology and society, v. 18, n. 1, artigo 33, 2013. Disponível em:

<https://www.ecologyandsociety.org/vol18/iss1/art33/>. Acesso em: 17 mar. 2019.

BRASIL. Ministério do Desenvolvimento Agrário (MDA). Secretaria Especial de Agricultura Familiar e do Desenvolvimento Agrário. Disponível em:

<http://www.mda.gov.br/sitemda/sites/sitemda/files/user_arquivos_64/CARTILHA_PAA_ FINAL.pdf >, acesso em: 03 fevereiros. 2019.

Lei $\mathrm{n}^{\circ} 11.326$ de 24 de julho de 2006. Estabelece as diretrizes para a formulação da Política Nacional da Agricultura Familiar e Empreendimentos Familiares Rurais. Disponível em: <www.planalto.gov.br/ccivil_03/_ato2004-2006/2006/lei/111326.htm> . Acesso em: 20 fev. 2018.

Decreto $n^{\circ}$ 8.473/15, de 22 de junho de 2015. Estabelece, no âmbito da Administração Pública federal, o percentual mínimo destinado à aquisição de gêneros alimentícios de agricultores familiares e suas organizações, empreendedores familiares rurais e demais beneficiários da Lei no 11.326 , de 24 de julho de 2006, e dá outras providências. Disponível em: <http://www.planalto.gov.br/ccivil_03/_Ato20152018/2015/Decreto/D8473.htm>. Acesso em: 01 fev. 2018.

Lei $\mathrm{n}^{\circ} 10.696$, de 02 de julho de 2003. Dispõe sobre a repactuação e o alongamento de dívidas oriundas de operações de crédito rural, e das outras providências. Disponível em: <www.planalto.gov.br/Ccivil_03/leis/2003/L10.696.htm>. Acesso em: 20 fev. 2019.

Lei $\mathrm{n}^{\circ}$ 12.512, de 14 de outubro de 2011. Institui o Programa de Apoio à Conservação Ambiental e o Programa de Fomento às Atividades Produtivas Rurais < www.planalto.gov.br/ccivil_03/_ato2011-2014/2011/lei/112512.htm>. Acesso em: 20 fev. 2019

Lei no 8.666, de 21 de junho de 1993. Regulamenta o artigo 37, inciso XXI, da Constituição Federal, institui normas para licitações e contratos da Administração Pública e dá outra providência.

CARDOSO, Univaldo Coelho. COOPERATIVA: Série Empreendimentos Coletivos. Brasília: Serviço Brasileiro de Apoio às Micro e Pequenas Empresas - SEBRAE, 2014.

COSTA, Amorim Júnior e SILVA. As Cooperativas de Agricultura Familiar e o Mercado de Compras Governamentais em Minas Gerais. Revista de Economia e Sociologia Rural, Piracicaba-SP, v. 53, n. 01, p. 109-126, Jan/Mar 2015 - Impressa em Abril de 2015. DOI: http://dx.doi.org/10.1590/1234-56781806-9479005301006. Acesso em: 31 de maio de 2020. 
CREMONESE, C.; SCHALLENBERGER, E. Cooperativismo e agricultura familiar na formação do espaço agrícola do oeste do Paraná. Tempo da Ciência. Cascavel, n. 12, v. 23 . pp. 49-63, 1. sem. 2005.

CUNHA, W. A. DA; FREITAS, A, F. DE; SALGADO; FIGUEIREDO, R. F. J. DOS. Efeitos dos Programas Governamentais de Aquisição de Alimentos para a Agricultura Familiar em Espera Feliz, MG. Revista de Economia e Sociologia Rural, Piracicaba-SP, v. 55, n. 3, p.427-444, set. 2017. Disponível em: <https://doi.org/10.1590/1234-5678180694790550301>. Acesso em: 25 de maio de 2020.

CUNHA, Wellington Alvim da; FREITAS, Alan Ferreira de; SALGADO, Rafael Junior dos Santos Figueiredo. Efeitos dos Programas Governamentais de Aquisição de Alimentos para a Agricultura Familiar em Espera Feliz, MG. Revista de Economia e Sociologia Rural, [s.1.], v. 55, n. 3, p. 427-444, set. 2017. FapUNIFESP (SciELO). http://dx.doi.org/10.1590/1234-56781806-94790550301. Acesso em 25 de maio 2020.

GRISA, Catia; SCHNEIDER, Sergio. Três gerações de políticas públicas para a agricultura familiar e formas de interação entre sociedade e estado no Brasil. Revista de Economia e Sociologia Rural, [s.1.], v. 52, n. 1, p. 125-146, 2014. FapUNIFESP (SciELO). http://dx.doi.org/10.1590/s0103-20032014000600007. Acesso em 15 mar. 2019.

Departamento de Estudos Sócio-Econômicos Rurais (Deser). O Programa de Aquisição de Alimentos e sua relação com a Política Nacional de Segurança Alimentar e Nutricional e a Política de Comercialização Agrícola no Brasil, entre 2003-07: Uma Avaliação. Curitiba: Deser; 2008.

Instituto Brasileiro de Geografia e estatística-. Censo Agropecuário 2017. Resultados preliminares. Disponível em: https://censos.ibge.gov.br/demografico/2010. Acesso em: 7 mar. 2019.

IBGE. Instituto Brasileiro de Geografia e Estatística. Disponível em: $<$ https://www.ibge.gov.br/estatisticas-novoportal/multidominio/condicoes-de-vidadesigualdade-e-pobreza/17270-pnad-continua.html>. Acesso em: 7 de ago. 2019.

JESUS, R. P. Associativismo no Brasil do século XIX: repertório crítico dos registros de sociedades no Conselho de Estado (1860-1889)". Locus - Revista de História. Juiz de Fora, vol. 13, n 1, p. 144-170, 2007. Disponível em: < http://www.scielo.br/scielo.php?script=sci_nlinks\&pid=S01046276201500010015700063\&lng=en>. Acesso em: 2 mar.2019.

JESUS, R. P. Associativismo no Brasil do século XIX: repertório crítico dos registros de sociedades no Conselho de Estado (1860-1889)". Locus - Revista de História. Juiz de Fora, vol. 13, no 1, p. 144-170, 2007. Disponível em: <

http://www.scielo.br/scielo.php?script=sci_nlinks\&pid=S0104$6276201500010015700063 \& \operatorname{lng}=\mathrm{en}>$. Acesso em: 2 mar.2019.

LAVALLE, A. G.; CASTELLO, G. As benesses desse mundo: associativismo religioso e inclusão socioeconômica. Novos Estudos, v. 68, p. 73-93, 2004.

LEOPOLDINO, C. B. Associativismo em Famílias de Autistas: A Gênese da Associação Fortaleza Azul. Revista Contribuciones a las Ciencias Sociales, Málaga, abr./jun. 2016. 
Disponível em: <http://www.eumed.net/rev/cccss/2016/02/autistas.html>. Acesso em: 21 mar.2019.

LEOPOLDINO, C. B. Associativismo em Famílias de Autistas: A Gênese da Associação Fortaleza Azul. Revista Contribuciones a las Ciencias Sociales, Málaga, abr./jun. 2016. Disponível em: <http://www.eumed.net/rev/cccss/2016/02/autistas.html>. Acesso em: 21 mar.2019.

Leonello, J. C. e Cosac, C. D. (2009). O Associativismo como Alternativa de Desenvolvimento Local e Sustentabilidade Social. Disponível em: http://www.estudosdotrabalho.org/anais6seminariodotrabalho/joaocarlosleonelloeclaudiam ariadahercosac.pdf. Acesso em: 20 de maio de 2021.

LOPES, S. F.; BAUER, C. Presença do associativismo das universidades estaduais paulistas

na história do sindicalismo educacional latinoamericano. Revista Ibero-Americana de Estudos em Educação, v. 10, n. 4, 2015.

MAGALHÃES, M. L.; SCHEMES, C. Mulheres e o associativismo negro em Novo Hamburgo (RS). Revista Latino-Americana de História, v. 2, n. 9, p. 217-232, 2014. MATTEI, L. Programa de Aquisição de Alimentos da Agricultura Familiar (PAA): antecedentes, concepção e composição geral do programa. Cadernos do CEAM (UnB) 2007; 7(1):33-44.

Marotti J, Galhardo A.P.M, Furuyama R.J, Pigozzo M.N, Campos TN, Laganá DC. Amostragem em pesquisa clínica: tamanho da amostra. Rev Odontol Univ Cid São Paulo 2008;20(2):186-94. Disponível em:

https://www.researchgate.net/profile/Juliana_Marotti/publication/285800533_Amostragem _em_pesquisa_clinica_Tamanho_da_amostra/links/566aca4008aea0892c4b9e11.pdf. Acesso em: 20 de maio de 20.

OLIVEIRA, A. R. O. Associativismo na região do Pontal do Paranapanema-SP: limites e possibilidades para o desenvolvimento rural. 2010. 209 f. Tese (Doutorado em Geografia) Universidade Estadual Paulista, Presidente Prudente, 2010. Disponível em:

$<$ https://repositorio.unesp.br/bitstream/handle/11449/105066/oliveira_ar_dr_prud.pdf?sequ ence=1>. Acesso em: 22 mar.2019.

OLIVEIRA, A. R. O. Associativismo na região do Pontal do Paranapanema-SP: limites e possibilidades para o desenvolvimento rural. 2010. 209 f. Tese (Doutorado em Geografia) Universidade Estadual Paulista, Presidente Prudente, 2010. Disponível em:

$<$ https://repositorio.unesp.br/bitstream/handle/11449/105066/oliveira_ar_dr_prud.pdf?sequ ence $=1>$. Acesso em: 22 mar. 2019 .

PERES, S. Cultura, política e identidade na Amazônia: o associativismo indígena no Baixo Rio Negro. Revista Anthropológicas, v. 14, n. 12, 2011

SANGALLI, A. R. et al Associativismo na agricultura familiar: Contribuições para o estudo do desenvolvimento no assentamento rural Lagoa Grande, em Dourados (MS), Brasil. Revista Organizações Rurais \& Agroindustriais, Lavras, v. 17, n. 2, p. 225 238, 2015. 
Santos AR, Vieira NS, Ferreira PR, Castro TTS. Agricultura familiar e Segurança Alimentar e Nutricional: análise dos resultados do programa de aquisição de alimentos (PAA doação simultânea) nos estados da Bahia e Minas Gerais. Cadernos Gestão Social 2012; 3(1):9-24.

SAMBUICHI, R. H. R., GALINDO, E. P., OLIVEIRA, M. A. C., PEREIRA, R. M. A diversificação produtiva como forma de viabilizar o desenvolvimento sustentável da agricultura familiar no Brasil. In L. M. Monasterio, M. C. Neri, \& S. S. D. Soares (Eds.), Brasil em desenvolvimento 2014: Estado, planejamento e políticas públicas. v. 2, p. 61-84. Brasília, Brasil: Ipea.

SCHNEIDER, S. Reflexões sobre diversidade e diversificação: agricultura, formas familiares e desenvolvimento rural. Ruris: revista do centro de estudos rurais, v. 4, n. 1, p. 85-131, 2010. Disponível em:

<https://www.ifch.unicamp.br/ojs/index.php/ruris/article/view/708>. Acesso em: 15 mar. 2019.

SICOOP- Sistema de Cooperativas de Crédito do Brasil Disponível: $<$ http://www.sicoobsc.com.br/altovale/noticias/tipos-de-cooperativas-os-13-ramosatuantes-brasil/>. Acesso em: 07 mar. 2019.

Silva ED, Almeida MF. Programa de Aquisição de Alimentos: tecendo os caminhos entre segurança alimentar e a política de sementes no semiárido paraibano. Cadernos de Agroecologia 2013; 8(2):1-6.

Souza, A. F., Loreto, M. das D. S. de. (2018). Repercussões do Programa de Aquisição de Alimentos (PAA) nas condições de produção e reprodução social dos agricultores familiares. Oikos: Família E Sociedade Em Debate, 29(2), 230-258.

https://doi.org/10.31423/oikos.v29i2.3790

SOUZA, José Thyago Aires et al. Associativismo, assistência técnica e extensão rural como

políticas públicas para a geração de desenvolvimento sustentável na agricultura familiar em

Taperoá-PB. Revista Brasileira de Geografia Física, v. 8, n. 2, p. 303-308, 2015.

TYGEL, D., Economia Solidária. In: FERRARO JUNIOR, L. A. Encontros e caminhos: formação de educadoras(es) ambientais e coletivos educadores. Brasília. MMA/DEA. 2013. Vol.3. P.93-103. 